\title{
Mirada al desnudo: poderes y placeres visuales en Salò de Pier Paolo Pasolini
}

\author{
Naked look: powers and visual pleasures \\ in Salò by Pier Paolo Pasolini
}

\author{
Roberto Marín Villalobos
}

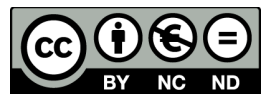

Esta obra está bajo una licencia Creative Commons Reconocimiento-No comercial-Sin Obra Derivada 


\title{
Mirada al desnudo: poderes y placeres visuales en Salò de Pier Paolo Pasolini
}

\author{
Naked look: powers and visual pleasures \\ in Salò by Pier Paolo Pasolini
}

\author{
Roberto Marín Villalobos ${ }^{1}$ \\ Universidad de Costa Rica \\ Costa Rica
}

Recibido: 19 de agosto de 2019 Aprobado: 26 de octubre de 2019

\begin{abstract}
Resumen
El presente artículo pretende analizar lo visual en interjuego con la desnudez, como catalizador del poder y el placer en la película Salò o le 120 giornate di Sodoma, última obra del director Pier Paolo Pasolini. Para ello, se efectúa un diálogo entre escenas del filme y algunos postulados conceptuales. Los diferentes usos de la desnudez y su tratamiento visual no solo dan cuenta de la maestría estética del director italiano, sino también de su potencial teórico para pensar una mirada sadeana, incluso sádica.
\end{abstract}

Palabras clave: mirada; desnudez; cine; psicoanálisis; Pasolini

\begin{abstract}
This article aims to analyze the visual in interplay with nudity, as a catalyst for power and pleasure in the film "Salò o le 120 giornate di Sodoma", the last work of the director Pier Paolo Pasolini. For this, a discussion is made between scenes from the film and some conceptual postulates. The different uses of nudity and its visual handling not only reflect the aesthetic mastery of the Italian director, but also his theoretical potential to think gaze in Sadean -even sadistic- terms.
\end{abstract}

Keywords: gaze; nudity; cinema; psychoanalysis; Pasolini

1 Docente, investigador y supervisor clínico de la Universidad de Costa Rica. Máster en Teoría Psicoanalítica por la misma universidad. ORCID: 0000-0002-4993-6497. Correo electrónico: edgarroberto.marin@ucr.ac.cr

ESCENA. Revista de las artes, 2020, Vol. 80, Núm. 1, pp. 233-246 ISSN 2215-4906 
El ser humano no es un ser manso, amable, a lo sumo capaz de defenderse si lo atacan, sino que es lícito atribuir a su dotación pulsional una buena cuota de agresividad. En consecuencia, el prójimo no es solamente un posible auxiliar y objeto sexual, sino una tentación para satisfacer en él la agresión, explotar su fuerza de trabajo sin resarcirlo, usarlo sexualmente sin su consentimiento, desposeerlo de su patrimonio, humillarlo, infligirle dolores, martirizarlo y asesinarlo. "Homo homini lupus": ¿quién, en vista de las experiencias de la vida y de la historia, osaría poner en entredicho tal apotegma?

(Freud, 1986 [1930], p. 108)

\section{Inspección introductoria: Anteinfierno ${ }^{2}$}

Pocas películas han sido tan controversiales como la última obra cinematográfica de Pier Paolo Pasolini: Salò o le 120 giornate di Sodoma, traducida como Saló o los 120 días de Sodoma ${ }^{3}$. Aun siendo

has been called nauseating, shocking, depraved, pornographic . . It's also a masterpiece... one of the most passionately debated films of all time, a thought-provoking inquiry into the political, social, and sexual dynamics that define the world we live in. [catalogada como nauseabunda, chocante, depravada, pornográfica... es también una obra maestra... una de las películas más apasionantemente debatidas de todos los tiempos, una indagación intelectualmente provocativa en las dinámicas políticas, sociales y sexuales que definen el mundo en el que vivimos] (The Criterion Collection, s.f., párr. 1).

Desde el título se alude a intertextos de renombrada fama sexual: la ciudad de Sodoma mencionada en el libro de Génesis que, a su vez, inspira el título de la obra del Marqués de Sade (1904) Les Cent Vingt Journées de Sodome, ou l'École du libertinage, traducida como Las 120 jornadas de Sodoma o la escuela de libertinaje. Este texto sirve de base para

${ }^{2}$ Cada uno de los subtítulos, a excepción del último, corresponden a los nombres de cada sección en la segmentación que Pasolini efectúa en su película.

${ }^{3}$ En adelante se hará referencia a la película con una versión abreviada de su título: "Saló". 
la adaptación presentada por Pasolini. Antes de entrar propiamente al tema de lo visual y de la desnudez, vale la pena echar un vistazo a esos intertextos, especialmente al texto bíblico, ya que en este la mirada tiene un papel particular.

La ciudad de Sodoma estaba sentenciada a ser destruida por parte de Jehová debido al pecado exacerbado de ese pueblo, pero, por el ruego de Abraham, logró que Lot y su familia se salvaran. Dos ángeles fueron enviados a casa de Lot con ese cometido, no obstante, los hombres de la ciudad rodearon el lugar exigiendo que los ángeles salieran de allí para "conocerlos", ante lo cual Lot optó por negociar: "He aquí ahora yo tengo dos hijas que no han conocido varón; os las sacaré fuera, y haced con ellas como bien os pareciere" (Génesis, 19:8)4 Sin embargo, los ángeles intervinieron, "y a los hombres que estaban a la puerta de la casa hirieron con ceguera desde el menor hasta el mayor, de manera que se fatigaban buscando la puerta" (19:11). Esto sirvió para que Lot, su esposa y sus dos hijas salieran de la ciudad. No obstante, la historia termina de manera singular: al salir de Sodoma "la mujer de Lot miró atrás, a espaldas de él, y se volvió estatua de sal" (19:26). Mientras que Lot y sus hijas lograron resguardarse en una cueva sin mirar atrás; la mayor dijo a su hermana: "Ven, demos a beber vino a nuestro padre, y durmamos con él, y conservemos de nuestro padre descendencia" (19:32). "Y las dos hijas de Lot concibieron de su padre" (19:36). El relato interesa principalmente por dos motivos:

El primero es la efectiva apetencia sexual de los pobladores de Sodoma, pues incluso desearon sexualmente a los ángeles, seres inmaculados, a lo que se suma la ocurrencia de lo incestuoso, las hijas que, con tal de que algún varón "entre a nosotras conforme a la costumbre de toda la tierra" (19:31), eligieron a su padre. Si bien es cierto que esto no era una práctica inusual según el mismo canon bíblico, llama la atención la necesidad de dar de beber vino a Lot, de tal manera que "él no echó de ver cuándo se acostó ella, ni cuándo se levantó" (19:35). Este "no echar de ver" se relaciona con el segundo motivo de interés por el cual se retoma este intertexto: la mirada. Tanto los ángeles cegaron a los hombres que rodeaban amenazantes la casa de Lot, como la esposa de este fue convertida en estatua por ver la destrucción de Sodoma, por mirar hacia atrás. Estos aspectos del relato ilustran una idea que se desarrollará a mayor profundidad con Saló, la cual consiste en que la mirada puede ser campo y propósito del poder, del placer, de la dominación.

Sirva un fragmento de la introducción del intertexto base de Saló, la obra de Sade, para ingresar a la desnudez y sus relaciones con lo visual: "Es ahora, querido lector, cuando tienes que preparar tu corazón y tu espíritu para el relato más impuro que haya sido nunca hecho desde que el mundo existe, ya que no se ha encontrado un libro parecido ni entre los

${ }^{4}$ Revisión de 1960 Reina-Valera, igualmente para las siguientes citas bíblicas. 
antiguos ni entre los modernos" (1904, p. 36), ¿y una película? Desde la sección del Anteinfierno se efectúa una inspección ocular, precisamente, relacionada con la pureza, pues el grupo de dieciocho jóvenes secuestrados son puestos bajo el examen de los cuatro libertinos: el duque, el obispo, el magistrado y el presidente. Primero, examinan a los jóvenes. El obispo se adelanta diciendo: “¿No deberíamos inspeccionarlos un poco mejor? Desnúdense" (Pasolini, 1976, 10:23-10:28). De inmediato, los dos jóvenes a quienes se les da la orden desnudan su torso, la cámara desciende hasta centrarse en un primer plano de sus penes, vuelve a subir a sus rostros, "Vístanse", exclama el duque. Ya desde esta escena se presenta la desnudez como un espectáculo de humillación, efectuado a través de órdenes o de ejercicio de poder. Precisamente, uno de los dos jóvenes -de nombre Sergio- es uno de los muchachos a los que los cuatro libertinos "agarran entre ojos", es decir, con especial saña.

Llega el turno de las jóvenes. "hazle ver a estos señores qué escondes aquí debajo, ¿eh?" (1976, 14:46-14:50), indica una de las señoras mientras desnuda a la primer muchacha, mostrándola, a su vez, al grupo de libertinos. La escena se da como una especie de venta, en la que esta señora ostenta la "mercancía" presentada: la joven desnudada. La segunda joven también entra vestida, pero a ella se la descarta de inmediato debido a que encuentran un diente defectuoso. La tercer joven, Renata, es traída sin ropa; además, se le revela a los cuatro libertinos que su madre murió ahogada intentando que no la capturaran y que todo ocurrió "ante los ojos de este ángel" (1976, 17:40-17:43), unos ojos llenos de lágrimas. No sobra mencionar que, ante esta tercera presentación, el grupo de libertinos se mostró más que complacido. En esta ocasión, la desnudez física y emocional parecen coincidir en un mismo juego de crueldad: ver y saber todo cuanto plazca, una especie de panóptico de lo biográfico.

\section{Segunda inspección: Círculo de las manías}

En esta segunda sección de Saló, también se da una inspección que no queda solamente en el plano físico, pues el relato de la señora Vaccari se ve interrumpido por una peculiar petición del presidente:

¡Un momento, señora Vaccari! Es necesario no omitir absolutamente ningún detalle. Es solo así que podrá mostrar aquellas formas de excitación... No sé absolutamente nada de las dimensiones del pene de su profesor. No sé absolutamente nada sobre el tipo de eyaculación, ni tampoco sé si le acarició los genitales o la obligó a tenerlo en la mano. En definitiva, querida señora Vaccari, un poco más de claridad. (1976, 25:47-26:49) 
Con esta solicitud queda vislumbrada la manera en la que incluso las narraciones de las señoras son examinadas minuciosamente, buscando dejar al descubierto todo pormenor de la historia. Cuerpos y relatos son desprovistos de cualquier atavío que impida su visualización total. Lo anterior concuerda con el estilo sadeano de escritura, generoso al punto de colmar sus historias con amplias descripciones de lugares, situaciones, personajes y acciones; como si brindara con sus letras un recorrido visual de arriba abajo, con primeros y primerísimos planos. Esto lleva a preguntar si la narrativa barroca de Sade no es una especie de guion para el trabajo de cámara en Saló, habida cuenta de la manía por el detalle presente en ambos textos.

Si bien es cierto, y como es de esperar, hay numerosos aspectos en los que Pasolini es congruente con el estilo y obra de Sade. Hay algunos en los que no, como es el caso, justamente, de la vestimenta y apariencia de los personajes. Esto debido a que en Las 120 jornadas de Sodoma o la escuela de libertinaje, el "divino Marqués" se enfoca en descripciones de los cuatro libertinos, sus consortes y las Señoras, mientras que de las víctimas jóvenes apenas se alude a una "belleza abstracta" (Hood, 2005, p. 79): la atención no está puesta en los objetos de placer, sino en las cualidades de quienes lo buscan. Huelga indicar que en esto último Pasolini también se aleja de Sade, pues las descripciones de los libertinos y las señoras son más bien imágenes de lo horrendo, decrépito y repulsivo, como en el caso de la descripción de la señora Desgranges:

Poco a poco se había convertido en un esqueleto que solo podía inspirar repugnancia. Su culo marchito, usado, marcado, desgarrado, parecía más bien cartón cuero que piel humana, y el agujero era tan ancho y arrugado que un grueso miembro podía penetrarlo a pelo sin que ella lo advirtiera. Para colmo de atractivos, esta generosa atleta de Citerea, herida en varios combates, tenía una teta de menos y tres dedos cortados. Cojeaba, le faltaban seis dientes y un ojo. (Sade, 1904, p. 19)

La descripción de Sade continúa con suposiciones sobre los trágicos eventos que esta mujer tuvo que soportar en su cuerpo para que haya quedado tan mal trecha. Lo que permite coincidir, nuevamente, la descripción física con la biográfica y hace de las cicatrices una escritura corporal de lo vivido. El cuerpo deviene entonces un espacio de inscripción (Melenotte, 2016).

La desadaptación cinematográfica de Pasolini respecto a la apariencia del conjunto de libertinos (los cuatro señores y las señoras relatoras), en el filme -incluída su vestimentaes más bien cuidada y opulenta; muy en contraste con la vestimenta sencilla de las y los jóvenes capturados. Aún más cuando se los desnuda en este círculo de las manías: desnudez al servir la primera cena, desnudez del público y, luego de los novios durante la boda, desnudez al imponérseles actuar y comer como perros apenas usando un collar; desnudez 
como afirmación de un estado de dominación (Foucault, 1984). Con ello podría conjeturarse que la contextualización de la película, efectivamente, provee un campo estético distinto, a pesar de tratarse de figuras de poder similares, el paso de la tiranía monárquica al fascismo italiano -en conjugación con la ocupación nazi- no deja de imprimir alguna marca. Es bien sabida la particular preocupación nazi por lo prolijo y espléndido de sus atuendos, pero también por el orden en general. Esto lleva a Hood a proponer que "las cifras [la contaduría de los libertinos de víctimas y castigos] recuerdan los informes burocráticos de los escuadrones de la muerte de la SS que trabajaban en los guetos de la Europa oriental" (2005, p. 84). Entonces, más que un abandono por parte de Pasolini de lo asqueroso, al velarlo de elegancia y asepsia, se da lugar a una acentuación de lo repulsivo, justamente debido a la presencia de lo glamoroso. La siguiente inspección resulta especialmente ilustrativa a este respecto.

\section{Tercera inspección: Círculo de la mierda}

En línea con la última idea mencionada, hay dos momentos en los que se plasma esta oscilación entre lo atractivo o lujoso y lo repugnante o inmundo. La primera de ellas es respecto a la relatora de este círculo, la señora Maggi. Luego de mostrar cómo se prepara con refinadas prendas y cosméticos, entra al Salón de Orgías a iniciar sus historias. Sin embargo, llega una nueva sugerencia promovida por el presidente, la cual consiste, a su vez, en una inspección: “¿Usted no piensa, signora Maggi, que sería adecuado, antes de empezar sus historias, que nos mostrara su mejor parte?... Se los decía, amigos: que un trasero tan extraordinario merecía ser visto. Puedo asegurar que hay pocos mejores" [destacado propio] (1976, 58:37-58:57). El placer es, una vez más, inaugurado en lo visual, en el que la señora Maggi pasa de mostrar su "trasero tan extraordinario" a la siguiente narración:

El cliente era una viejo General de la policía. Me hizo desvestirlo y ponerle un pañal. Habituada a extrañezas parecidas, atendí sus disposiciones. Poco después empecé a tener fuertes cólicos en el vientre [le habían suministrado laxantes]. El hombre se alegró y me obligó a defecar ante sus ojos, cosa que hice sin la menor vergüenza. Me obligó a recoger parte de mis excrementos con los dedos, y alimentarlo como a un bebé. Todo se desarrolló según la práctica. Se lo tragó todo, imitó los llantos de un bebé y eyaculó en su pañal. (1976, 01:00:40-01:01:21)

El relato es evidentemente impresionante. Sin embargo, yendo más allá del posible repudio (¿o interés?) inicial ante lo grotesco del episodio relatado, "vale la pena" detenerse al menos en dos asuntos: la desnudez/vestimenta y la observación de la evacuación fecal. Ya se ha mencionado cómo la desnudez y cierto tipo de vestimenta sirven para el ejercicio del poder, particularmente del poder visual. No obstante, en esta ocasión, es la figura de poder quien solicita ser desnudado y vestido como un bebé, ¿hay alguna contradicción en 
esto? Puede argumentarse que no, pues en pleno ejercicio de su poder, el General obliga a esta mujer a desvestirlo y colocarle pañales, es decir, que el personaje tiene el poder de ser dominado, y con este poder, el placer que le representa esta nueva y temporal posición. Esta movilidad parcial es descrita por Foucault a propósito de un constructo ya mencionado, los estados de dominación:

en los cuales las relaciones de poder, en lugar de ser móviles y permitir a los diferentes miembros una estrategia que los modifique, se encuentran bloqueadas y fijadas. Cuando un individuo o un grupo social llegan a bloquear un campo de relaciones de poder, a volverlo inmóvil y fijo y a impedir toda reversibilidad del movimiento -con instrumentos que pueden ser tanto económicos como políticos o militares-, se está frente a lo que se puede llamar un estado de dominación. Es cierto que, en tal estado, las prácticas de libertad no existen o no existen sino unilateralmente o son extremadamente demarcadas y limitadas. (1984, p. 259)

En otras palabras, el general de Policía -este detalle es significativo- puede descolocarse de ese rango, cuanto menos de forma artificial y fugaz ${ }^{5}$. Quizá de manera similar a lo que buscan algunas personas con grandes fortunas al pagar para vivir experiencias que le son ajenas, como la indigencia y la prostitución, también de forma efímera, sabiendo que cuando quieran pueden volver al estado de dominación usual (Diario 26, 3 de noviembre, 2007). Puede que la misma Saló brinde a la audiencia la oportunidad de una aproximación parecida, en este caso, a la coprofagia, sin terminar embarrados de sustancia fecal. Sin embargo, en un plano más simbólico, puede que los ojos del público espectador sí se salpiquen de mierda -aquí entra el segundo punto destacado del relato de la señora, además del segundo ejemplo de la oscilación lujo/desecho-, pues así como dicho general de Policía obliga a la joven Maggi a defecar siendo vista, Pasolini nos presenta frontalmente un aperitivo visual escatológico. Se trata de la escena en la que Renata es obligada a comer desnuda y del piso un trozo de excremento recién defecado por el Duque, quien le ofrece una cucharilla de plata para hacerlo. He ahí el efecto estético de contraste: comer heces con fina cubertería.

Sirva esta escena para interpelar a Freud, quien sin mayores miramientos se abocó al estudio de lo anal. En cuanto a este ámbito, interesa, en primera instancia, el péndulo estético elegancia-inmundicia, que para este autor -en este caso en particular- tiene un

5 No obstante, y siguiendo una de las propuestas centrales de Lacan (2009) en su texto Kant con Sade, este general podría no estar sometido a nadie, pero sí y muy intensamente a algo: al poder, dominado por la dominación, así como Kant y Sade estaban sometidos a una misma moral, aunque diametralmente opuesta. 
carácter esperable, tal y como se aprecia en la siguiente observación clínica: "un joven y espiritual filósofo, con actitudes estéticas exquisitas, se apresura a enderezarse la raya del pantalón antes de acostarse para la primera sesión; revela haber sido antaño un coprófilo de extremo refinamiento, como cabía esperarlo del posterior esteta" (1986 [1913], p. 139). Si bien es cierto, en este ejemplo se postula una suerte de distanciamiento temporal entre ambas tendencias, en Saló son presentadas al unísono, lo que causa un impacto o efecto más estremecedor. En segunda instancia, interesa la dinámica retención-expulsión, ya que, para Freud, el esfínter anal posee un carácter regulador, uno de los primeros que el humano conquista en su desarrollo psicosexual (1986 [1905]). Esto -especialmente en caso de alguna fijación- tendrá luego sus ecos en el afán por el orden y la limpieza, vale decir un afán de control que no se queda en lo higiénico o estético, sino también en lo político. Esta es una de las enseñanzas de Pasolini pues, en Saló, dicho control somático-político también está presente, ya no de forma meramente simbólica, sino concreta, ya que dentro de las reglas provistas por los libertinos se cuenta la retención de deposiciones. En este asunto toma también relevancia el control visual o de inspección, dado que se obliga a los y las jóvenes cautivas a revelar sus respectivas letrinas, así como la zona entre sus nalgas en búsqueda de algún indicio de excreción no permitida. El éxtasis ocurre en un banquete de mierda, en el que son servidas y consumidas las deposiciones acumuladas por días. El control de los cuerpos y sus funciones no solo ocurren en este tipo de escenarios extremos, sino también en instituciones totales (Goffman, 1972) y educativas. Incluso de manera mucho más generalizada y atenuada en los controles ejercidos a través de disposiciones biopolíticas: dónde, cómo, con quiénes, por cuánto tiempo, qué es visto y qué no, entre otros asuntos, al defecar. De nuevo, tales disposiciones obedecen a cuestiones de índole tanto sanitaria como ideológica, sino ¿por qué usualmente los servicios sanitarios públicos están divididos según género?, ¿no hay acaso en esto una ambigüedad (o ironía) sexual?

En todo caso, parece obedecer a un influjo cultural y no deja de ser llamativo que Freud se refiera a este asunto en El malestar en la cultura. De este texto interesan principalmente dos fragmentos que serán citados in extenso, debido a la relevancia que revisten. El primero de ellos ilustra y apoya algunos de los argumentos ya planteados:

La impulsión a la limpieza corresponde al esfuerzo [drang] por eliminar los excrementos que se han vuelto desagradables para la percepción sensorial. Sabemos que entre los niños pequeños no ocurre lo mismo. Los excrementos no excitan aversión ninguna en el niño, le parecen valiosos como parte desprendida de su cuerpo. La educación presiona aquí con particular energía para apresurar el inminente curso del desarrollo, destinado a restar valor a los excrementos, a volverlos asquerosos, horrorosos y repugnantes. (1986 [1930], p. 98) 
Con esto puede plantearse un nexo entre esta depreciación y ocultamiento de los excrementos con el respectivo pudor (mezcla de repulsión y pena) vinculado a la exposición de genitales, es decir, la desnudez. Puede que la situación extrema sea la de ser visto desnudo y además excretando. Cuestión que Pasolini tampoco deja intacta, cabe recordar la ocasión en la que el obispo obliga a una joven a orinar y además a verlo haciéndolo, acto antecedido por la frase: "tienes dos bonitos ojos para mirar... ¡Ahora, mira!" (1976, 50:12-50:16). En relación con el primer intertexto citado en este escrito, en el Génesis (3:7-10) se encuentra un pasaje en el que la desnudez, la mirada y, en esta ocasión, el miedo, guardan relación entre sí, pues luego de haber comido del fruto del árbol prohibido:

${ }^{7}$ Entonces fueron abiertos los ojos de ambos, y conocieron que estaban desnudos; entonces cosieron hojas de higuera, y se hicieron delantales. ${ }^{8}$ Y oyeron la voz de Jehová Dios que se paseaba en el huerto, al aire del día; y el hombre y su mujer se escondieron de la presencia de Jehová Dios entre los árboles del huerto. ${ }^{9}$ Mas Jehová Dios llamó al hombre, y le dijo: ¿Dónde estás tú? ${ }^{10}$ Y él respondió: Oí tu voz en el huerto, y tuve miedo, porque estaba desnudo; y me escondí. [destacado propio]

La voz paseante resulta en vigilancia ante la cual Adán y Eva se ocultan, aunque queda un tanto nebuloso por qué la desnudez engendra miedo. Puede suponerse que esa apertura de ojos es una toma de conciencia (¿consciencia de sí o conciencia de tipo moral?), ante la cual ocurren dos ocultamientos: con los delantales de higuera -una mítica primera prenda- y con los arboles del huerto. Curiosamente, se esconden con elementos arbóreos, mismo objeto de su desobediencia. Cierta articulación de vergüenza y miedo puede encontrarse en otro "génesis", ahora freudiano, que corresponde al segundo fragmento anunciado de El malestar en la cultura:

Ahora bien, el relegamiento de los estímulos olfatorios parece ser, a su vez, consecuencia del extrañamiento del ser humano respecto de la tierra, de la adopción de una postura erecta en la marcha, que vuelve visibles y necesitados de protección los genitales hasta entonces encubiertos y así provoca la vergüenza. Por consiguiente, en el comienzo del fatal proceso de la cultura se situaría la postura vertical del ser humano. [destacado propio] (1986 [1930], p. 97)

Se alude a una teoría, no comprobada, sobre el origen de la cultura y a la desprotección al verse desnudo; lo llamativo es la congruencia con el relato bíblico en cuanto a la necesidad de ocultamiento visual de lo genital, así como de la preponderancia de lo visible. El imperio de la vista o "hipergravitación de los estímulos visuales" (Freud, 1986 [1930], p. 98) coincide con la hipótesis del oculocentrismo civilizatorio y no solo en tiempos modernos 
(o si se quiere posmodernos), pese a que podría sostenerse que, en las últimas décadas ha acontecido todo un auge visual-imaginario o un régimen escópico (Hernández-Navarro, 2006; 2007), pues el ojo ha tenido indiscutiblemente una función evolutiva primordial.

Respecto a las funciones, en Saló, el orificio anal no solo cumple un papel excretor, sino también y muy fervientemente receptor, asunto que, nuevamente, es adivinable desde el título.

\section{Cuarta inspección: Círculo de la sangre}

Sade... sadismo. Tanto Sade como Sodoma corrieron con la suerte de que a partir de sus nombres se acuñaran términos de uso ya popular. El título de esta sección denota violencia, agresión, dolor, sadismo sangriento. Es con esto que se inaugura el tercer y último círculo, pues la inspección final tiene como propósito decidir quién tiene el mejor culo, para proceder a matarlo o matarla. Este examen es efectuado a oscuras, utilizando apenas una linterna y colocando a las y los jóvenes desnudos e inclinados con su cabeza tocando el suelo de tal manera que sus genitales no sean visibles, esto para que la diferenciación sexual anatómica no influencie la decisión de los cuatro devenidos jurados. Con este sutil detalle, se muestra una vez más cómo no solo la desnudez, sino también su eclipse o semi-desnudez, comportan una erótica que conjura poder y placer. La dialéctica examinador-examinado en función de lo visual también tiene un correlato psicoanalítico pues, en otra observación clínica, en esta ocasión sobre el diván, Freud apunta que "es habitual que el paciente tome como una privación esta situación que se le impone y se revuelva contra ella, en particular si la pulsión de ver (el voyeurismo) desempeña un papel significativo en su neurosis" [destacado propio] (1986 [1913], p. 135). ¿Pueden analizantes sentirse como las y los jóvenes de Saló? Quizá, y tal vez no solo por esta disposición (anti)visual que implica el diván, sino por -y esto relacionado con la manía por el detalle o desnudez biográfica- el "verse" hablando de cosas que se preferiría mantener veladas. En buena medida, lo anterior llevó a Foucault a ubicar al psicoanálisis como una práctica confesional de raigambre cristiana (Foucault, 2005); tema discutido e incluso refutado (Allouch, 1998), pero no del todo acabado (Sanfelippo, 2017). Quien se analiza se somete a un método: la asociación libre. ¡Particular paradoja: someterse a la libertad!

Todavía en diálogo con el psicoanálisis y en retorno a Saló, el clímax visual-agresivo se presenta hacia el final de la película. Antes de entrar a la descripción de la escena, se hace menester traer a colación otra anotación freudiana en la que se engarzan algunos de los elementos aquí discutidos. En el texto Presentación autobiográfica, Freud agrega dos "pares de opuestos (sadismo-masoquismo, pulsión de ver-pulsión de exhibición)" (1986 [1925], p. 34), con lo cual empareja el sadismo a la pulsión de ver o voyerismo. Estas 
dicotomías son debatibles ${ }^{6}$, pues, como ya se ha problematizado con Pasolini (1976), el exhibicionismo puede ser tanto sádico como masoquista, lo mismo que el voyerismo. No obstante, frente a estados de dominación más que a relaciones móviles de poder, estas posiciones sí tienden a cristalizarse en el caso de Saló. Este "sadismo visual" también se encuentra relacionado con lo escatológico: "El que no es limpio, o sea, el que no oculta sus excrementos, ultraja entonces al otro, no muestra miramiento alguno por él" [destacado propio] (Freud, 1986 [1930], p. 98), y ni qué decir si se exige su ingesta. Cabe recordar, además, que en la fase anal "se ve afirmarse el sadomasoquismo en relación con el desarrollo del dominio muscular" (Laplanche, 1996, p. 145). En otras palabras, cierto sadomasoquismo primitivo corporal guarda estrecha relación con lo que es (re)velado a los demás, sean excrementos, genitales, alguna otra intimidad o secreto. Puede que en esto, por cierto, haya alguna resonancia metafórica con el chisme, el poder-placer por desnudar lo oculto del otro.

\section{Retrospección: Estatua de Sal(ó)}

La última escena de Saló puede servir para la conclusión y/o discusión final a desarrollar, a propósito de la posibilidad de una mirada agresiva. Dicha escena es toda una sinfonía de excentricidades visuales: las fatales torturas ocurren en un patio abierto a plena luz del día, hay desnudamientos y desnudez, los libertinos toman turnos para torturar, pero especialmente para sentarse en un palco con vista al patio. La silla del palco tiene un apoyo para la cabeza con morfología ocular, miran a través de binoculares y -de forma inédita dentro de la película misma- Pasolini hace mirar a la audiencia como ven los libertinos, enmarcando la perspectiva visual en un contorno que asemeja la negrura producida al ver a través de los cilindros del aparato. Este recurso estético no solamente implica una perspectiva visual en primera persona, sino que acerca lo suficiente al público espectador a una experiencia de sádico refinamiento: por instantes, el grupo de cuatro libertinos se expande y quien ve el filme es convertido en el quinto miembro del grupo: el duque, el obispo, el magistrado, el presidente y el espectador.

La maestría narrativa visual de Pasolini, en este punto, es congruente, a su vez, con el estilo sadeano de escritura, en el que constantemente interpela a su "querido lector", pero lo trasciende, pues no se deja al público como receptor pasivo de un relato, sino que lo hace cómplice. ¿Puede la persona espectadora resistirse a esta terrible participación? Argumentaría que no, justamente ahí reside el principal gesto sádico y sadeano de Pasolini: retirar la

${ }^{6}$ Lacan (2010) subvierte el tema de la mirada más allá del par ver-ser visto; incluso extrapolándolo de la vista misma. 
vista, cerrar los ojos, no terminar o ni siquiera empezar a ver la película, incluso fascinarse con ella, son todas victorias de la prolija impureza de Saló. La sodomía es visual. Ahora toca cerrar círculos, no en el sentido psicológico gestáltico, ni de los de manía, mierda y sangre, sino los círculos oculares. Después de todo: "'ni el sol ni la muerte pueden mirarse fijamente', como lo señaló La Rochefoucauld, lo mismo ocurre con respecto a Sade" (Le Brun, 2008, p. 10); esa estrella del dolor y la muerte que, con sus potentes letras, desnuda lo sanguinario del alma.

\section{Referencias:}

Allouch, J. (1998). El psicoanálisis, una erotología de pasaje. Córdoba: Edelp.

Diario26 (3 de noviembre, 2007). Cansados de los lujos, millonarios rusos pagan por vivir como indigentes. Diario26 [Periódico en línea]. Recuperado de: https://www.diario26. com/53170--cansados-de-los-lujos-millonarios-rusos-pagan-por-vivir-como-indigentes

Foucault, M. (2005). El poder psiquiátrico. Buenos Aires: FCE.

Foucault, M. (1984). La ética del cuidado de sí como práctica de la libertad. Diego Fonti (trad.). Entrevista con H. Becker, R. Fornet-Betancourt, A. Gomez-Müller. Tomado del sitio web https://revistas.unc.edu.ar/index.php/NOMBRES/article/viewFile/2276/1217

Freud, S. (1986 [1905]). Tres ensayos para una teoría sexual. En: Obras Completas, Tomo VII. Buenos Aires: Amorrortu editores.

Freud, S. (1986 [1913]). Sobre la iniciación del tratamiento (Nuevos consejos sobre la técnica del psicoanálisis. I). En Obras Completas, Tomo XII. Buenos Aires: Amorrurtu editores.

Freud, S. (1986 [1925]). Presentación autobiográfica. En Obras completas. Tomo XX. Buenos Aires: Amorrurtu editores.

Freud, S. (1986 [1930]). El malestar en la cultura. En Obras completas. Tomo XXI. Buenos Aires: Amorrurtu editores.

Goffman, I. (1972). Internados: Ensayos sobre la situación social de los enfermos mentales. Buenos Aires: Amorrortu Editores

Hernández-Navarro, M. (2006). El arte contemporáneo entre la experiencia, lo antivisual y lo siniestro. Revista Occidente, 297, 7-25

Hernández-Navarro, M. (2007). Resistencia a la imagen (Mary Kelly, La balada de la antivisualidad). Revista de Estudios Visuales, 4(1), 71-98

Hood, S. (2005). Marqués de Sade para Principiantes. Buenos Aires: Era Naciente.

Lacan, J. (2009). Escritos II. México: Siglo XXI. 
Mirada al desnudo: poderes y placeres visuales en Salò de Artículos

Pier Paolo Pasolini

Lacan, J. (2010). Seminario 11. Los cuatro conceptos fundamentales del psicoanálisis. Buenos Aires: Paidós.

Laplanche, J. (1996). Diccionario de psicoanálisis. Barcelona: Paidós.

Le Brun, A. (2008). Sade. De pronto un bloque de abismo... (Trad. Silvio Mattoni). Argentina: Ediciones literales en coedición con El cuenco de Plata.

Melenotte, G-H. (2016). El latigazo significante. Cuadernos de Psicoanálisis, 4(1), 93-102.

Pasolini, P. (director) y Grimaldi, A. (productor). (1976). Salò or the 120 days of Sodom. [Película]. Italia y Francia: Produzioni Europee Associate y Les Productions Artistes Associés

Sade, D-A-F. (1904). Las 120 jornadas de Sodoma. LibroDot [versión electrónica]. Tomado de http://www.librodot.com

Sanfelippo, L. (2017). Confesión y práctica psicoanalítica. Algunos contrapuntos entre M. Foucault y J. Lacan. Perspectivas en Psicología, 14(1), 86-95. Tomado de www.seadpsi.com.ar/revistas/index.php/pep/article/download/307/pdf

The Criterion Collection. (s.f.). Salò, or the 120 day of Sodom. [Página web]. Recuperado de: https://www.criterion.com/films/532-sal-or-the-120-days-of-sodom 